Article

\title{
Pitfalls Associated with Discriminating Mixed-Species Biofilms by Flow Cytometry
}

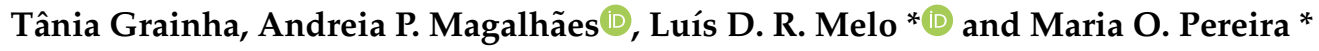 \\ Centre of Biological Engineering, LIBRO_Laboratório de Investigação em Biofilmes Rosário Oliveira, \\ University of Minho, Campus de Gualtar, 4710-057 Braga, Portugal; taniagrainha@ceb.uminho.pt (T.G.); \\ amagalhaes@ceb.uminho.pt (A.P.M.) \\ * Correspondence: lmelo@deb.uminho.pt (L.D.R.M.); mopereira@deb.uminho.pt (M.O.P.); \\ Tel.: +351-253-601-989 (L.D.R.M.); +351-253-604-402 (M.O.P.)
}

Received: 10 September 2020; Accepted: 21 October 2020; Published: 27 October 2020

\begin{abstract}
Since biofilms are ubiquitous in different settings and act as sources of disease for humans, reliable methods to characterize and quantify these microbial communities are required. Numerous techniques have been employed, but most of them are unidirectional, labor intensive and time consuming. Although flow cytometry (FCM) can be a reliable choice to quickly provide a multiparametric analysis, there are still few applications on biofilms, and even less on the study of inter-kingdom communities. This work aimed to give insights into the application of FCM in order to more comprehensively analyze mixed-species biofilms, formed by different Pseudomonas aeruginosa and Candida albicans strains, before and after exposure to antimicrobials. For comparison purposes, biofilm culturability was also assessed determining colony-forming units. The results showed that some aspects, namely the microbial strain used, the morphological state of the cells and the biofilm matrix, make the accurate analysis of FCM data difficult. These aspects were even more challenging when double-species biofilms were being inspected, as they could engender data misinterpretations. The outcomes draw our attention towards the need to always take into consideration the characteristics of the biofilm samples to be analyzed through FCM, and undoubtedly link to the need for optimization of the processes tailored for each particular case study.
\end{abstract}

Keywords: Pseudomonas aeruginosa; Candida albicans; mixed-species biofilm analysis; flow cytometry

\section{Introduction}

The ability of microorganisms to form a biofilm is an important feature in clinical, industrial and environmental settings [1]. Biofilms are well-structured microbial communities adhered to biotic or abiotic surfaces enclosed within a self-produced extracellular polymeric matrix. The matrix is the major structural component of the biofilm [2] and is denominated as an extracellular polymeric substance (EPS). The EPS is composed of polysaccharides, proteins, nucleic acids, lipids and other biopolymers such as humic substances [3]. Most natural biofilms are polymicrobial and all members of the community contribute with their own EPS components, resulting in a more complex matrix [4].

The biofilms associated with numerous infectious diseases (e.g., infections of oral cavity, otitis, cystic fibrosis) are described as being of a polymicrobial nature with bacteria coexisting with pathogenic yeasts or filamentous fungi [5]. Pseudomonas aeruginosa is a ubiquitous bacterium and an opportunistic pathogen frequently isolated from healthy humans as part of the human microbiota and can coexist in mixed infections with the polymorphic fungus Candida albicans [6,7]. C. albicans is a commensal yeast able to initiate invasive growth and develop health problems in compromised individuals [8,9]. Notably, C. albicans is one of the few fungal species causing disease in humans [10]. P. aeruginosa and C. albicans represent an example of co-infection and are commonly related with chronic and healthcare-associated 
infections [11-13]. From a clinical point of view, it is crucial to entirely characterize the biofilm populations (single- and mixed-species) and understand the mechanisms underlying the changes that occur during co-infection as result of the established interactions. The monitoring of polymicrobial communities is routinely performed by culture-dependent approaches that require appropriate selective media and optimal growth conditions and is hindered by the presence of cells in a viable but poorly culturable state or underestimated by the presence of cellular aggregates $[14,15]$. Under these circumstances, standard microbiology methods are often unsuitable to diagnose polymicrobial biofilm infections. Molecular methodologies, such as quantitative real-time PCR (qPCR) $[16,17]$ or fluorescence in situ hybridization using peptide nucleic acids (PNA FISH) [18-20], have helped in the characterization of members of microbial communities, affording a specific and sensitive quantification of specific species in biofilm samples that are unable to be detected by culturable methods. Nevertheless, these approaches cannot distinguish cellular subpopulations. Thus, flow cytometry (FCM) could present an accurate alternative to the analysis of biofilm cells, since it enables detailed investigation of cellular subpopulations due to its ability to perform multiparametric single-cell analysis [21]. The analysis of biofilm communities by this technique is particularly useful, since it allows a quick achievement of cell counts and provides an overview about the type of cells present in the samples, namely their size and complexity. In addition, this method allows for the discrimination between live and dead cells, also providing information about damaged cells [22]. Based on this, the goal of this study was to explore FCM analysis to characterize and discriminate mixed-species biofilm samples before and after being challenged by antimicrobial treatments.

Accordingly, the aspects that can influence FCM analysis as well as tips to circumvent them are presented through this work.

\section{Results}

\subsection{Planktonic versus Biofilm Cells}

Before biofilm analysis by FCM, an optimization of the process is desirable to adjust all sample analysis parameters. Firstly, as bacteria might be in the FCM detection limit, owing to its small size, a preliminary optimization was performed in order to guarantee the accurate detection of P. aeruginosa and thus the reliability of the results. Due to the complexity and heterogeneity of biofilms, optimizations using planktonic cells were performed. Since P. aeruginosa and C. albicans have distinct sizes and the flow cytometer allows for separation by size and complexity, it was assumed that their distinction on mixed communities should be well achieved using the same dyes. As can be observed in the dot plot (Figure 1), it was possible to define gates for each single-species planktonic culture tested.

Before examining the mixed-species biofilms, single-species biofilms of both species were also analyzed. The results obtained for these biological samples showed that cells from C. albicans biofilm populations are very different on cell size and complexity from the planktonic cells, leading to gating adjustments (Figure 1). In addition to the typical fungal cell gate previously defined for the planktonic cultures, several fluorescently labeled events up to the demarcated bacterial region were detected (Figure 2). To check whether this feature was particular for the C. albicans SC5314 strain, two more strains of each studied species (P. aeruginosa and C. albicans) were analyzed both on planktonic and biofilm states. Although this effect was not observed for P. aeruginosa PAO1, two more P. aeruginosa strains were also analyzed to strengthen the absence of that behavior. While this effect was not observed for any of the P. aeruginosa strains (Supplementary Figure S1), it was consistent on all C. albicans strains tested (Supplementary Figure S2). 


\section{P. aeruginosa PAO1}

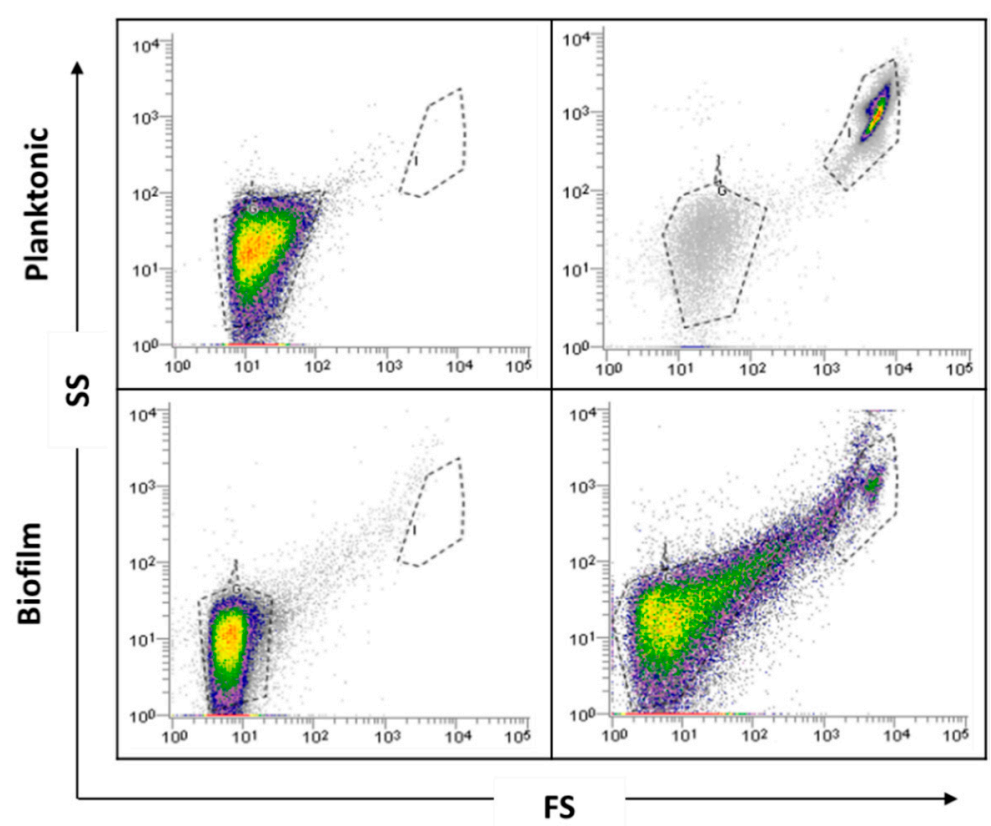

Figure 1. Representative dot plots obtained for planktonic cells and single biofilms of $P$. aeruginosa PAO1 and C. albicans SC5314 by flow cytometry (FCM).

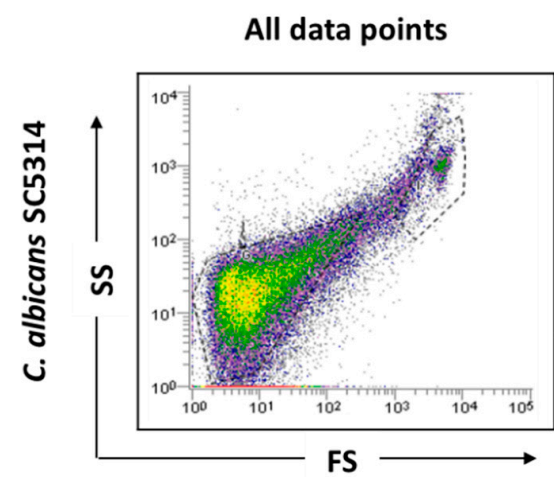

Dot plot C. albicans

Dot plot $P$. aeruginosa

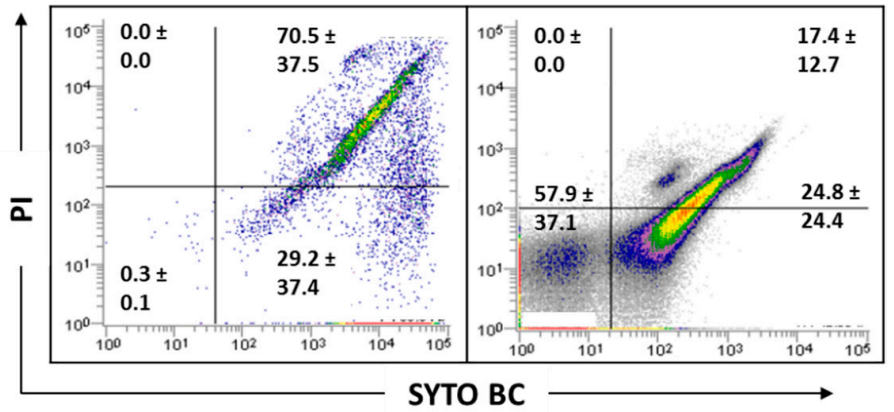

Figure 2. Representative dot plots obtained for C. albicans SC5314 biofilm by FCM. In 'all data points', the dot plots SS (Side Scatter) $\times$ FS (Forward Scatter) are represented, as acquired in the logarithm. Dot plots of $P$. aeruginosa and $C$. albicans represent the areas delineated to represent bacteria and fungi, respectively.

\subsection{Effect of Hyphae and Biofilm Matrix on Flow Cytometry Analysis}

In an attempt to understand the factors generating the differences observed in the C. albicans biofilm populations in comparison with planktonic cultures, two possibilities were inspected, the impact of hyphal growth and the effect of the biofilm matrix. Since $C$. albicans biofilm cells present different phases of growth, it is expected that cells with distinct hyphal lengths are also present. Additionally, the biofilms were grown in Roswell Park Memorial Institute (RPMI) 1640, a medium that favors hyphal growth; therefore, more elongated hyphae could appear in these samples compared with planktonic cultures [23]. Based on this knowledge, the possibility of hyphal growth introducing some heterogeneity in the population, with a consequent interference in the results, was raised. To evaluate this hypothesis, planktonic cultures of C. albicans SC5314 grown in Sabouraud Dextrose Broth (SDB) and in RPMI supplemented with serum $2 \%(v / v)$, to induce hyphal cell growth, were analyzed. It was noticed that the fungal population which had hyphae induction became more heterogenous (Supplementary Figure S3), thus allowing us to verify that the presence of hyphae could account for the observed 
differences. However, a closer inspection of the results for C. albicans 547096, a strain that does not have the ability to form hyphae in both planktonic and biofilm conditions, allowed us to notice a change between both modes of growth (Supplementary Figure S2). Despite it being clear that hyphal growth has some influence on the results, this did not entirely explain what happened in biofilm samples.

To deeply understand what influenced the results obtained in the biofilm samples, the possible interference of the biofilm matrix was also evaluated. The EPS matrix is composed of large amounts of eDNA $[3,24]$ that can be bounded by the used fluorochromes, but, due to its small size, is only detected by the cytometer when it is attached to other matrix components. Therefore, efforts were done to extract the biofilm matrix, then the biofilm cells with and without the matrix were analyzed on the cytometer. The FCM of the biofilm matrix samples revealed a similar pattern to that obtained previously for C. albicans biofilms (Figure 3). Although this alteration between planktonic and biofilm samples was not previously clearly detected for $P$. aeruginosa strains, the analyses of the biofilm matrix samples allowed us to notice that the EPS matrix also play a role in the bacterial biofilm cell counts (Figure 3).
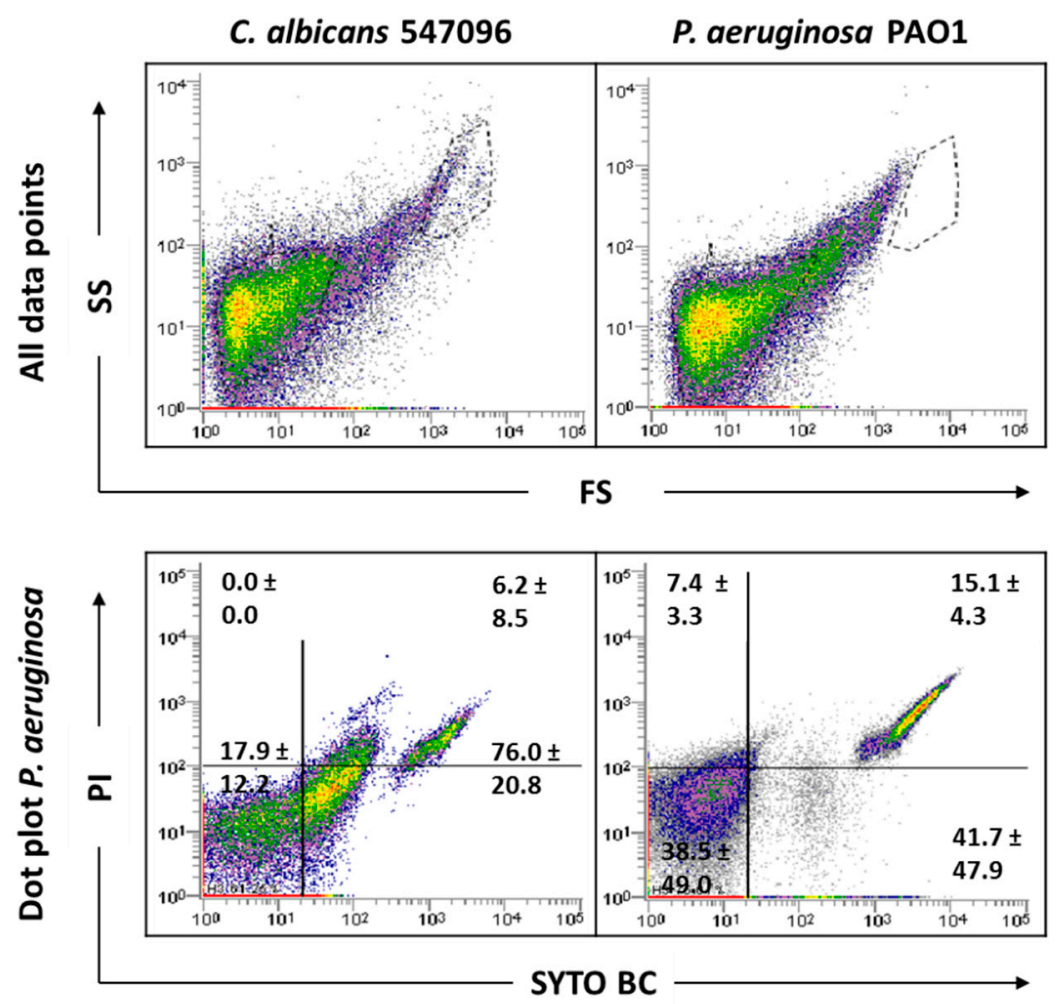

Figure 3. Representative dot plots obtained for biofilm matrix of C. albicans 547096 and P. aeruginosa PAO1 by FCM. In 'all data points', the dot plots SS (Side Scatter) $\times$ FS (Forward Scatter) are represented, as acquired in the logarithm. The dot plot of $P$. aeruginosa represents the areas delineated to represent bacteria.

The results indicate that both hyphal growth and the biofilm matrix account for altering the typical gate observed in C. albicans planktonic cultures. However, the presence of the EPS matrix has been shown to have greater impact on the FCM analysis. Although the P. aeruginosa gate does not differ between planktonic and biofilm, it was also evident that the matrix influences FCM analysis.

Overall, the data clearly highlighted that biofilm matrix extraction, before FCM analysis, is a requirement for this kind of methodology. Otherwise, it will not be possible to accurately analyze biofilm populations, due to the risk of populations not being properly differentiated, and consequently causing cell counts to be severely influenced by positively marked matrix events. 


\subsection{Influence of Sonication on Biofilm Cell Viability}

As this study has mixed-species biofilms as the main focus, a sonication procedure was used based on a previous optimized protocol. The sonication time was evaluated to ensure that this procedure did not result in cell lysis (Supplementary information Figure S4). The results indicated that the matrix extraction with $30 \mathrm{~s}$ of sonication at $30 \%$ amplitude was not harmful to any of the strains tested $(p<0.05)$. However, these sonication conditions were not effective in removing the entire matrix of C. albicans SC5314 and 324LA/94 strains (Supplementary Figure S5). As can be observed in Figure 4, although some matrix has been removed from $C$. albicans 324LA/94 samples, the cellular suspensions still present some matrix traces, which are being gated where $P$. aeruginosa is usually gated, making the study of mixed-species biofilms containing this C. albicans strain unfeasible.
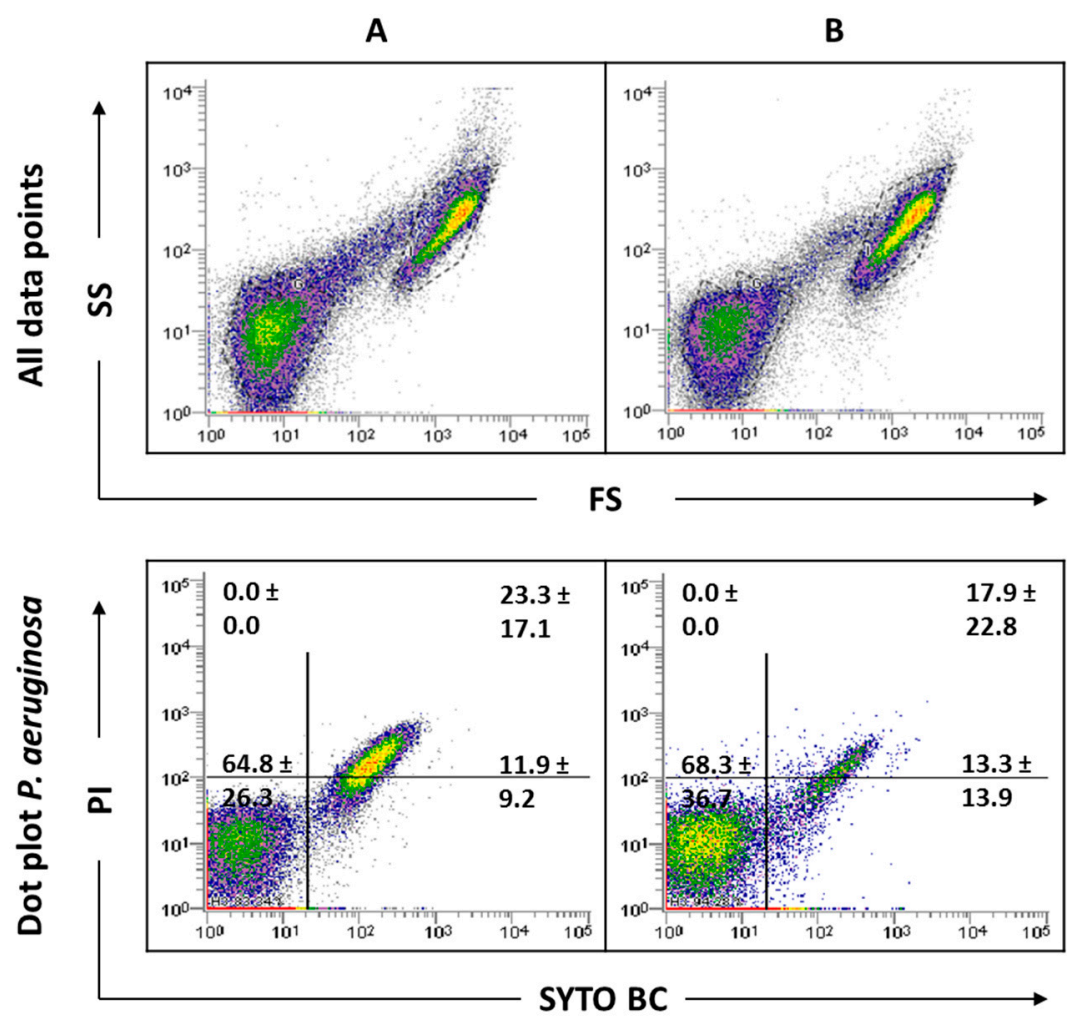

Figure 4. Representative dot plots obtained by FCM for C. albicans 324LA/94 biofilms before (A) and after (B) extraction of biofilm matrix.

\subsection{Analysis of Mixed-Species Biofilms}

To focus and frame the study, the number of strains used in the mixed biofilm formation were narrowed to one strain for each organism. In the case of P. aeruginosa, as no differences were observed between the strains tested in the FCM data analysis, the PAO1 strain was selected, because it is one of the most commonly used strains for biofilm research. Regarding C. albicans, to minimize the effects of the biofilm matrix and to eliminate hyphae influence, 547096 was the strain selected. The sonication parameters were tested in these mixed-species biofilms, and the results show that the matrix was effectively extracted (Figure 5). 

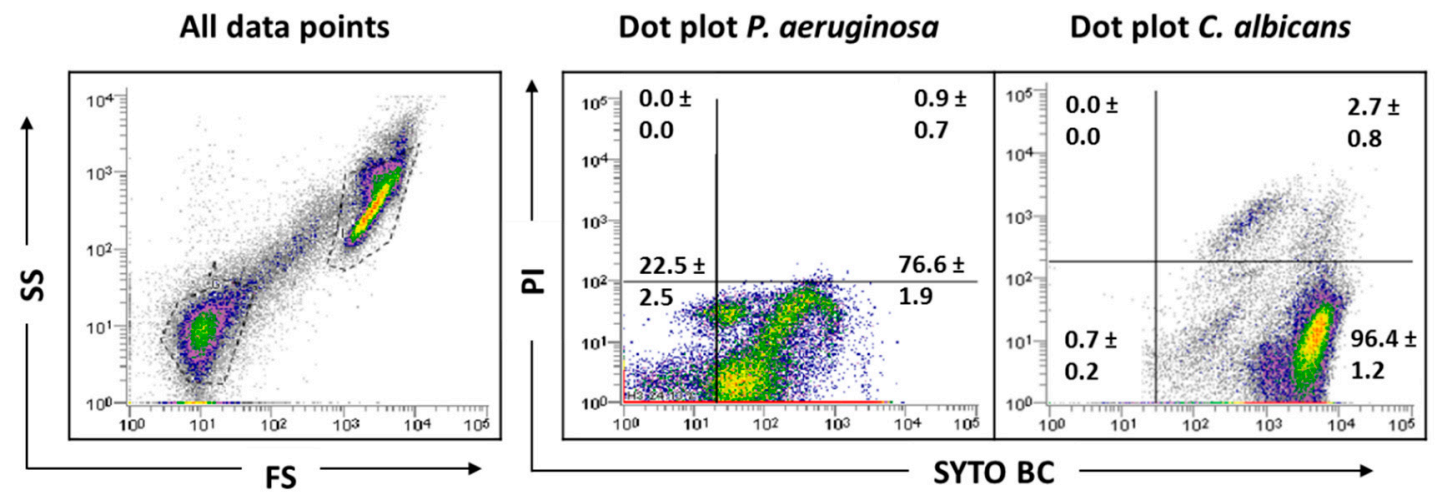

Figure 5. Representative dot plots obtained for P. aeruginosa PAO1 and C. albicans 547096 mixed-species biofilms by FCM. In 'all data points', the dot plots SS (Side Scatter) $\times$ FS (Forward Scatter) are represented, as acquired in the logarithm. Dot plots of P. aeruginosa and C. albicans represent the areas delineated to represent bacteria and fungi, respectively.

Indeed, the results showed a clear and distinct separation between bacterial and fungi populations, making the evaluation of this consortium by FCM possible. Since the C. albicans matrix, which was gated where P. aeruginosa is usually gated, does not appear because it was removed, bacterial cells will be more feasible counted.

\subsection{Antimicrobial Effect on Mixed-Species Biofilms}

Pre-established polymicrobial biofilms were treated with ciprofloxacin or linalool and their antimicrobial effect was evaluated by FCM (Figure 6) and colony-forming units (CFU) were counted (Table 1).

Table 1. FCM counting and colony-forming units (CFU) enumeration of pre-established mixed biofilms treated with two different concentrations of ciprofloxacin and linalool. Both 24 and 48 h-old untreated biofilms are included for comparison purposes. $\log _{10}$ values represent means \pm standard deviations (sd).

\begin{tabular}{ccccc}
\hline \multirow{2}{*}{ Condition } & \multicolumn{2}{c}{ P. aeruginosa } & \multicolumn{2}{c}{ C. albicans } \\
\cline { 2 - 5 } & FCM Counts/mL & CFU/mL & $\begin{array}{c}\text { FCM } \\
\text { Counts/mL }\end{array}$ & CFU/mL \\
\hline 24 h-old biofilm & $5.69 \pm 0.03$ & $6.99 \pm 0.45$ & $6.11 \pm 0,17$ & $6.51 \pm 0.55$ \\
48 h-old biofilm & $7.37 \pm 0.02$ & $8.53 \pm 0.48$ & $6.87 \pm 0.10$ & $7.46 \pm 0.69$ \\
Ciprofloxacin (0.25 mg/L) & $5.36 \pm 0.24^{\#}$ & $6.08 \pm 0.94^{\#}$ & $6.44 \pm 0.23$ & $6.64 \pm 0.82$ \\
Ciprofloxacin (8 mg/L) & $4.85 \pm 0.62^{\#}$ & $4.99 \pm 1.31 * \#$ & $6.43 \pm 0.23$ & $6.82 \pm 0.44$ \\
Linalool (0.3\% v/v) & $6.26 \pm 0.21$ & $7.62 \pm 0.70$ & $6.07 \pm 0.19$ & $2.02 \pm 1.91^{*, \#}$ \\
Linalool $(1.2 \%$ v/v) & $6.27 \pm 0.07$ & $7.38 \pm 0.41$ & $6.28 \pm 0.03$ & $0.00^{*, \#}$ \\
\hline
\end{tabular}

* Significantly different compared with 24 h-old biofilm control $(p<0.05)$. \# Significantly different compared with 48 h-old untreated biofilm $(p<0.05)$. 
A

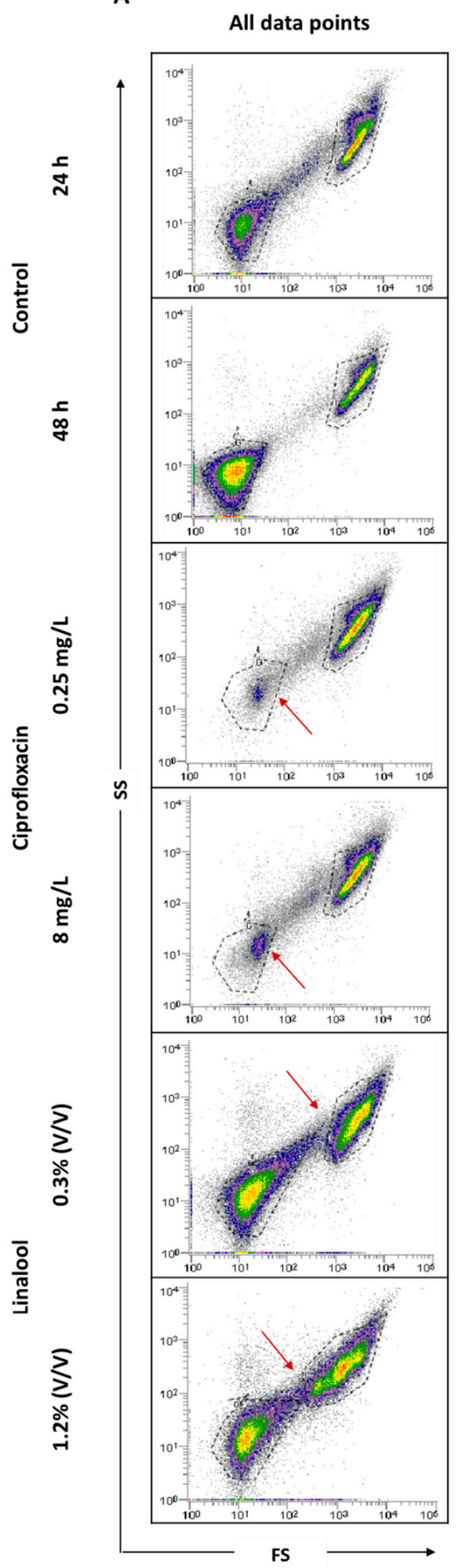
B

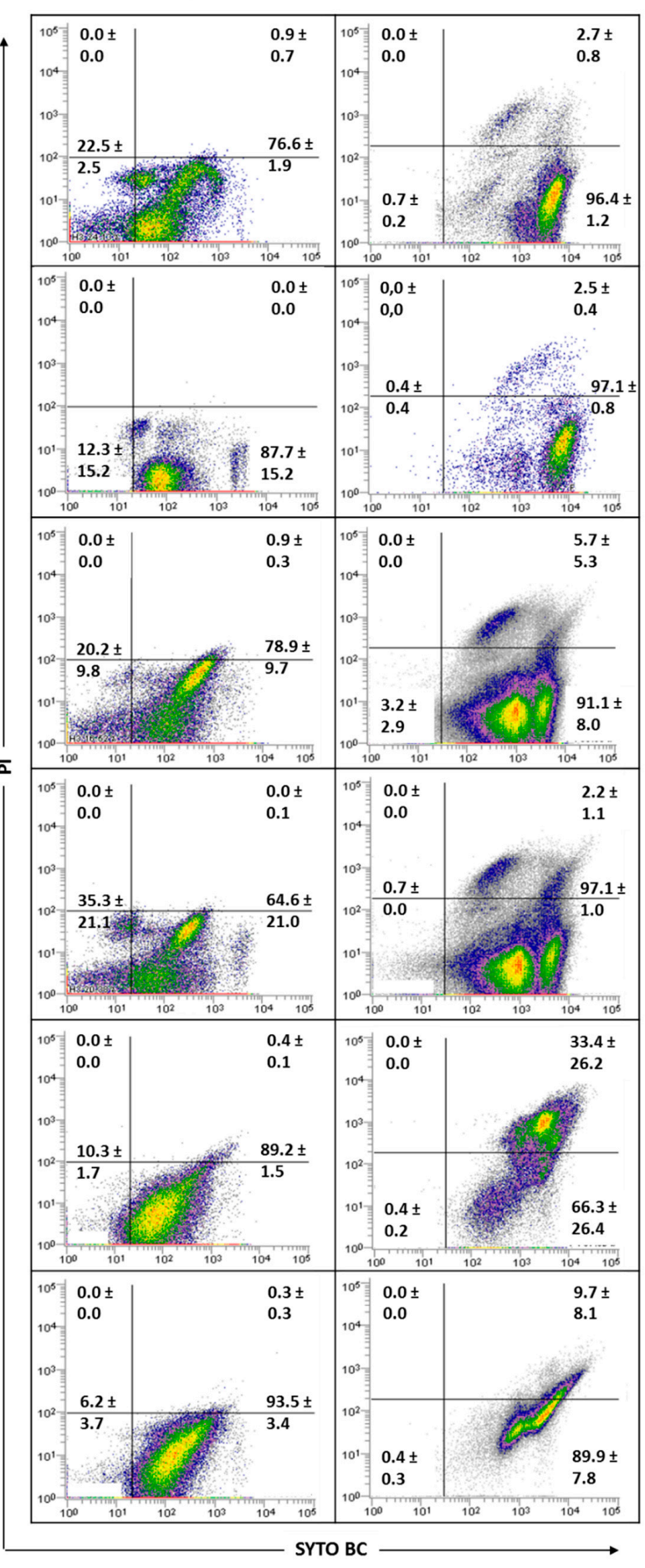

Figure 6. Representative all data points (A) and specific dot plots (B) obtained for P. aeruginosa PAO1 and C. albicans 547096 mixed-species biofilms by FCM. Dot plots of P. aeruginosa and C. albicans represent the areas delineated to represent bacteria and fungi, respectively. The arrows indicate alterations in the core of the population compared to the controls.

To understand the effect of the antimicrobials tested, it was considered important to verify the behavior of the total population in terms of size (FS) and complexity (SS). Figure 6 displays the graphs of all data points obtained for 24 and 48 h-old biofilms, and for the populations after antimicrobial 
treatments. The analysis of the dot plots indicated that there are no evident changes when comparing the $24 \mathrm{~h}$-old biofilms of P. aeruginosa and C. albicans with the corresponding $48 \mathrm{~h}$. The core of the fungal population presented a slight increase in the SYTO BC mean fluorescence intensity (MFI) from 2189 to 4208. Regarding the effect of the antimicrobials, the data revealed that, when using both ciprofloxacin concentrations, the core of the P. aeruginosa population is altered compared with the controls. In terms of viability, ciprofloxacin treatment does not appear to affect $P$. aeruginosa biofilm cells. In the case of C. albicans, no notable differences in terms of size and complexity were observed. Nevertheless, the yeast population seemed to be slightly destabilized, with the observation of two sub-populations, as well as a decrease in the SYTO BC uptake and an increase in the propidium iodide (PI) uptake compared with the 24 h-old biofilm control. These differences were more pronounced with the lowest concentration of ciprofloxacin ranging from 2182 to 1072 for SYTO BC MFI, and from 580 to 692 for PI MFI.

Using linalool, P. aeruginosa and C. albicans populations appeared altered, being more dispersed, suggesting a more heterogeneous population. With both linalool concentrations, C. albicans cells presented a reduced size and complexity (Figure 6). A population displacement along the PI axis was also observed, meaning that part of the cells is double stained. Furthermore, we observed a decrease in the SYTO BC uptake compared with the control, whereas SYTO BC MFI ranged from 2189 to 1604 and 1715 with the lowest and the highest concentration, respectively. Concerning P. aeruginosa populations, there was no effect observed in terms of viability and only a slight decrease in SYTO BC MFI was detected (from 117 in 24 h-old biofilm to 84 after biofilm treatment).

The cellular quantifications of the untreated and treated mixed biofilms are gathered in Table 1. Overall, FCM counts were somewhat lower than those detected by CFU, except when mixed biofilms were challenged with linalool, wherein C. albicans CFU counts were very low or even null. However, it must be taken into consideration that the standard deviation values associated with the CFU counts are higher than those observed for FCM, which might suggest more data variability between experiments.

Regarding the FCM results (Table 1) for P. aeruginosa, no significant differences were observed between ciprofloxacin-treated biofilms and the 24 h-old biofilm control. Furthermore, around 2 and 2.5-log reductions were achieved with the lowest and highest concentrations of ciprofloxacin, respectively, compared to the 48 h-old untreated biofilm. Taking into consideration CFU counts, the application of ciprofloxacin gave rise to some reductions in P. aeruginosa cells, notably when the higher concentration was used (about 2 and 3.5-log reductions compared with 24 and 48 h-old untreated biofilm, respectively). Ciprofloxacin treatment had no relevant effect on C. albicans as cell numbers remain unchanged for both concentrations, whatever the method used for biofilm cell counting.

The use of linalool had no relevant effect on $P$. aeruginosa viability and culturability compared with the 24 h-old biofilms. However, when compared with 48 h-old biofilms, although not statistically significant, about a 1-log reduction was observed when using either FCM or CFU. Concerning the fungus population in the mixed consortia, the use of FCM or CFU to count biofilm cells challenged by linalool gave rise to very distinct scenarios $(p<0.05)$. Indeed, through FCM, no significant alterations in the number of cells were noticeable in comparison with the respective controls. However, CFU counts revealed a clear negative effect of linalool in C. albicans culturability, achieving reductions of more than 4 or 5 -log compared to the 24 or 48 h-old untreated biofilms, and even total eradication with the highest linalool concentration.

\section{Discussion}

The polymicrobial nature of most infections [5] leads to the growing need for the study of these complex communities. Currently, there are several techniques that can be employed to perform biofilm analysis that are often dependent on the investigation purpose. Although FCM has been essentially applied for studying planktonic cultures [25], there are some studies using biofilms [26-28]. Pan et al. (2014) compared three methods (FCM, CFU and a spectrophotometry method of optical density measurement) for the quantification of bacterial cells after exposure to nanoparticles and 
found that FCM measurement was the quickest and most accurate method for bacterial detection [29]. This methodology has also been successfully applied in the study of single-species biofilms and to investigate bacterial physiological responses $[26,27]$. FCM was also successfully applied in the study of cell viability in planktonic mixed cultures, using Gram-specific fluorescent staining [30].

Since the study of polymicrobial biofilm communities using FCM is less common, the rationale behind this study was to exploit and fruitfully apply this technique in the characterization and quantification of mixed-species biofilms while paying attention to the eventual hitches that this technique could engender and trying and to find solutions to surpass them.

Biofilms are complex microbial communities in which cells are embedded in an EPS matrix that cements cells together and provides heterogeneous microenvironments, leading to cells adopting different physiological states. Thus, biofilm cells differ phenotypically from their planktonic counterparts [31]. The results obtained in this study have shown that the analysis of biofilm cell viability using FCM is not straightforward, essentially due to the presence of cells with different morphologies and the biofilm matrix. C. albicans biofilms are typically formed by a mixture of vegetative cells, pseudohyphae and hyphae [32], with this mixture of morphologies having been detected by FCM. Due to the size and complexity of fungal cells, it was noticed that the counts made by FCM were influenced by the presence of hyphae, since they can be counted as more than a single event (Supplementary Figure S3).

The EPS matrix represents a significant part of the biofilms, playing an important role in their development and cohesion [33-35]. The matrix is suggested as the biofilms' house [36] because it protects biofilm cells from physical, chemical and biological adversities. The biofilm matrix contains several constituents, including eDNA $[3,24]$, which, once attached to other matrix components, may be counted as positive events when passed in the flow cytometer, as highlighted by Figure 3. When the biofilm matrix was analyzed, several fluorescently labeled events, from the fungal cell gate previously defined up to the demarcated bacterial region, were detected. This squeezing of the events on the FS axis might be due to the heterogeneity of biofilm matrix components. These aspects may explain the impossibility of distinguishing the bacterial and fungal populations present in mixed cultures. Thus, matrix extraction is a crucial step before biofilm analysis by FCM. There are different methods that have been described for the extraction of EPS from single- and mixed-species biofilms, including centrifugation, filtration, heating, blending, sonication and treatments with agents or resins [37]. The EPS isolation method selected should be adapted accordingly to the type of biofilm under investigation. In the case of mixed-species biofilms, the selection and optimization of the extraction procedure was even more difficult. Moreover, it has to be taken into account that if the process becomes too complex or time consuming, the advantage of using FCM is lost. Sample sonication was the chosen methodology, but the matrix was not effectively extracted for the three C. albicans strains tested (Supplementary Figure S5) meaning that the success of the matrix extraction was strain dependent. These findings require longer sonication times and/or amplitudes to be tested in order to increase the amount of matrix extracted. Although it is known that sonication is an extraction method whose parameter optimization is microorganism dependent, in the case of mixed biofilms, there must be a commitment to reconcile the best possible parameters for all species present in the consortia. Thus, a reasonable time of sonication for both microbes present in the mixed cultures must be chosen, once the desirable target is achieved wherein the process does not affect the cellular viability of any of the tested species.

Based on previous studies, it can be assumed that, when using the same concentrations of antimicrobials agents, a greater antimicrobial effect occurs on planktonic cells, when comparing to the effect observed on biofilm cells, namely for ciprofloxacin [38] and linalool [39] towards P. aeruginosa and C. albicans, respectively. It is expected that, following an antimicrobial treatment, the composition and state of microbial populations might be altered [40]. Although, in some cases, there were no evident changes in the number of cells, it is important to emphasize some variations in SYTO BC and/or PI MFI, as well as variations in the core of the population (Figure 6). Ciprofloxacin is a 
broad-spectrum antibiotic of the fluoroquinolone class that acts on DNA gyrase (topoisomerase II) and topoisomerase IV, resulting in the inhibition of DNA replication, recombination and transcription, and thus causing bacterial death [41]. Ciprofloxacin affected the size and complexity of P. aeruginosa (Figure 6) and, regarding the results obtained by FCM, both concentrations of ciprofloxacin showed a bacteriostatic effect (Table 1) as the number of cells was lower after treatment compared with the 48 h-old untreated biofilm. Concerning CFU results, in addition to its bacteriostatic activity, a bactericidal activity was also observed to be more pronounced with the highest concentration of the antibiotic. These discrepancies between different methods are in accordance with the results observed by other authors [42]. Though ciprofloxacin is a bactericidal antibiotic according to classical testing, which uses planktonic cells, it is well known that cells from biofilm are more tolerant to the actions of antibiotics and harder to eradicate. Biofilm cells usually require higher doses to be eradicated by an antimicrobial [43]. The bacteriostatic effect observed here is due to the fact that cells were grown embedded in a biofilm. Both bacteriostatic and bactericidal effects of ciprofloxacin were previously reported in Escherichia coli [42]. Taking the $24 \mathrm{~h}$-old biofilms as the reference, the application of ciprofloxacin did not alter the number of $C$. albicans cells; however, when the comparison is made with the 48 h-old untreated biofilm, a decrease in the number of cells was observed. These results indicate that ciprofloxacin might also have a fungistatic effect. Moreover, it was observed that the C. albicans population was divided into two sub-populations, shifted to the left with a reduced uptake of SYTO BC (Figure 6), meaning that a diminished metabolism of viable cells after ciprofloxacin treatment may have occurred. Indeed, a decrease in staining intensity was previously associated as an indicative characteristic of decreased metabolic state $[26,44]$. Although fluoroquinolones have no intrinsic antifungal growth-inhibitory activity, topoisomerase I and II are found in pathogenic fungi [45-47], which suggests that ciprofloxacin might be a strong candidate to interact with antifungal agents [48-50]. Linalool is a terpene alcohol commonly found as a component of the essential oils of aromatic plants. This compound has been reported as having antifungal activity, specifically against C. albicans [51,52]. A more recent study showed that linalool suppressed the expression of several virulence-related genes [53]. The effect of linalool on C. albicans cells showed marked differences between FCM and CFU counts. Although C. albicans did not suffer reductions in terms of FCM counts, the number of $\mathrm{CFU}$ was diminished after linalool application, meaning that their growth ability was affected. Even though no reduction in the FCM counts was observed, a clear alteration in population diversity, as well as a shift in the fungus population along the PI axis, was observed (Figure 6), meaning that cells are double stained with SYTO BC and PI. This increase in the number of cells being double stained suggests that linalool damages the cell membrane, allowing PI to enter into the cells. Thus, it can be assumed that part of the cell is in an intermediate physiological state between life and cell death, which may explain the reduction in the ability of fungi to grow on solid media. A double-stained population is considered injured, as discussed by Léonard et al. [54]. Therefore, the discrepancy between CFU and FCM counts may be explained by the emergence of viable but non-culturable cells; nonetheless, an additional non-culture-based method would be valuable to unambiguously assure this hypothesis. Indeed, the exposure of cell populations to antimicrobial action can lead to the appearance of different cell subpopulations, particularly an increase in the number of viable but non-culturable cells $[55,56]$. The differences here observed reflect the problem associated with CFU counting, since it does not allow for the detection of viable but non-culturable cells. Differences between culturable and FCM counts were previously reported by other authors [26,44]. The abovementioned linalool membrane effect was also observed in other studies, where it was reported that this antimicrobial agent acts by causing the disruption of the membrane integrity and interrupting the cell cycle [51,57]. Concerning P. aeruginosa, the application of both linalool concentrations did not alter the number of cells when compared to the 24 h-old biofilm control, but caused a decrease when the 48 h-old untreated biofilms were used for comparison, meaning that that linalool might have bacteriostatic activity. Similar bacteriostatic effects of linalool were previously reported for other bacteria, namely 
Enterobacter cloacae, E. coli, Proteus mirabilis, Salmonella enteritidis, Salmonella typhimurium, Staphylococcus epidermidis and Listeria monocytogenes [58].

In addition to the discrepancies between FCM and CFU counts already mentioned, others were also observed (Table 1). In most cases, the number of culturable cells was higher than the FCM counts. This fact can be explained by the presence of injured cells that can reverse their state on fresh culture media and thus recover their growth ability. Moreover, in general, CFU results have higher variability between experiments, which leads to less accurate results.

Overall, this study showed that FCM can be a reliable methodology for the study of mixed-species biofilms, allowing for the discrimination of the stakeholders. However, for each consortium, previous optimization procedures must be followed, namely biofilm matrix extraction methodologies. Moreover, it was demonstrated that, when FCM is applied to scrutinize the mode of action of antimicrobial treatments, new insights can be provided due to the multiparametric analysis this technique allows.

A great step forward in the present research would be the clinical implementation of this methodology. Once the protocol is well developed and it is routinely applied, it is expected that it would be applied to real biofilm communities in clinical settings using blood samples or other samples where microorganisms are founded. Although FCM has been employed much more in the field of hematology, it has already been studied in different contexts. Microbial detection by FCM has already been proven to be possible using blood samples, as demonstrated in a previous work [59]. Clinical microbiology has undergone important changes during the last few years. Indeed, in recent years, microbiological techniques used in laboratories have been increasingly complemented by cutting-edge technologies such as FCM. The use of these practices presents several advantages to others, such as culture-dependent methods or microscopic approaches, since it provides multiparametric single-cell analysis very rapidly.

\section{Materials and Methods}

\subsection{Microorganisms and Culture Conditions}

Three reference strains of P. aeruginosa, two non-mucoid strains (PAO1 and UCBPP-PA14 (PA14)) and a mucoid strain (ATCC 39324), were used throughout this work. In addition, two clinical isolates of C. albicans (324LA/94, an oral isolate obtained from the culture collection of Cardiff Dental School (Cardiff, UK) and 547096, a urinary isolate obtained from the culture collection of the Biofilm Group of the Centre of Biological Engineering (Braga, Portugal)), and a reference strain, SC5314, were tested.

Prior to each assay, P. aeruginosa and C. albicans strains were subcultured from the frozen stock preparations onto Tryptic Soy Agar (TSA) and Sabouraud Dextrose Agar (SDA) plates, respectively. TSA and SDA were prepared from Tryptic Soy Broth (TSB; Liofilchem S.r.l., Roseto, Italy) or SDB (Liofilchem) supplemented with $1.2 \%(w / v)$ agar (Liofilchem). The plates were then incubated aerobically at $37^{\circ} \mathrm{C}$ for $18-24 \mathrm{~h}$.

Pure liquid cultures (pre-inocula) of $P$. aeruginosa were grown overnight in TSB, whereas C. albicans was maintained in SDB. For biofilm assays, $0.22 \mu \mathrm{m}$ of filter-sterilized RPMI 1640 medium (Gibco ${ }^{\circledR}$ by Life Technologies ${ }^{\mathrm{TM}}$, Grand Island, NY, USA) at $\mathrm{pH} 7.0$ was used.

\subsection{Biofilm Formation}

Biofilm assays were performed as previously described [60], with some modifications. Briefly, the initial cell suspension (pre-inocula) was centrifuged $\left(3000 \times g, 4{ }^{\circ} \mathrm{C}, 10 \mathrm{~min}\right.$ ) and the pellet resuspended in RPMI 1640 to achieve a concentration of $\sim 1 \times 10^{7} \mathrm{CFU}$ per mL. Bacterial concentration was estimated using an ELISA microtiter plate reader at an optical density of $640 \mathrm{~nm}\left(\mathrm{OD}_{640} \mathrm{~nm}\right)$ (Sunrise-Basic Tecan, Männedorf, Switzerland), while yeast cells were enumerated by microscopy using a Neubauer counting chamber. For mixed-species cultures, a combination of $50 \%$ of the suspended inoculum of each species was used. Cellular suspensions were further transferred to 24-well plates 
(Orange Scientific, Braine-l'Alleud, Belgium). Plates were then incubated aerobically for $24 \mathrm{~h}$ on a horizontal shaker at $120 \mathrm{rpm}$ and $37^{\circ} \mathrm{C}$.

\subsection{Hyphal Induction}

In order to promote hyphal growth of C. albicans cells, planktonic cultures of C. albicans S5314 were grown overnight in RPMI supplemented with $2 \%(v / v)$ fetal bovine serum (Biochrom AG, Berlin, Germany) at $120 \mathrm{rpm}$ and $37^{\circ} \mathrm{C}$. Cells were then analyzed by FCM.

\subsection{Biofilm Quantification}

\subsubsection{Determination of Culturable Cells}

After biofilm formation, wells were washed twice with sterile water after discarding the planktonic fraction. Afterwards, $500 \mu \mathrm{L}$ of phosphate-buffered saline (PBS; $10 \mathrm{mM}$ potassium phosphate, $150 \mathrm{mM} \mathrm{NaCl}$; pH 7.0) was added to each well and the biofilms were scraped. In order to ensure the reproducibility of the scraping method, the conditions were strictly followed in all experiments by using a pipette tip and scraping each well about $1 \mathrm{~min}$. To remove any aggregates, biofilm suspensions were vigorously vortexed (V1-Plus Biosan, Riga, Latvia) for $30 \mathrm{~s}$. The resulting biofilm suspensions were then serially diluted in sterile water and plated onto agar plates (TSA for P. aeruginosa and SDA for C. albicans) for single-species biofilms. For mixed-species biofilms, Pseudomonas Isolation Agar (PIA; Sigma-Aldrich, St. Louis, MO, USA) and SDA supplemented with $30 \mathrm{mg} / \mathrm{L}$ gentamycin (Sigma-Aldrich, St. Louis, MO, USA) (to suppress the growth of P. aeruginosa) were used for the specific isolation of $P$. aeruginosa and C. albicans, respectively. Agar plates were incubated aerobically at $37^{\circ} \mathrm{C}$ for $24-48 \mathrm{~h}$ for culturable cell counting. Values of culturable sessile cells were expressed as $\log _{10} \mathrm{CFU}$ per mL and represent the average of the triplicates for each strain. At least two independent experiments were carried out in duplicate.

\subsubsection{Extraction of Biofilm Matrix}

For the extraction of the biofilm matrix, a previously described protocol was followed [61]. In brief, after washing and scraping the biofilm, all suspensions were sonicated for $30 \mathrm{~s}$ at $30 \%$ amplitude in a sonicator (Cole-Parmer 750-Watt Ultrasonic Homogenizer, Vernon Hills, IL, USA). The cells were then separated from the matrix by centrifugation at $3000 \times \mathrm{g}$ for $5 \mathrm{~min}$ at $4{ }^{\circ} \mathrm{C}$. The supernatant was filtered with a membrane pore size of $0.2 \mu \mathrm{m}$. The pellet, which corresponds to the cells of a biofilm without matrix, was resuspended in $1 \mathrm{~mL}$ of PBS to be analyzed further.

\subsubsection{Flow Cytometry Assay}

Biofilm cell viability was also determined by FCM. In brief, pre-formed biofilms were washed twice, scraped in $1 \mathrm{~mL}$ of PBS, vortexed at maximum speed (30 s) and analyzed by cytometry. In addition, the biofilm cells (without the EPS matrix) and the EPS matrix itself (after matrix extraction procedure) were also analyzed. Lastly, $0.5-2 \mu \mathrm{M}$ of SYTO BC (Invitrogen ${ }^{\mathrm{TM}}$, Carlsbad, CA, USA) and $15 \mu \mathrm{M}$ of PI (Invitrogen ${ }^{\mathrm{TM}}$, Carlsbad, CA, USA) were added to the tested suspensions. Samples were incubated in the dark for $20 \mathrm{~min}$, at room temperature, and were analyzed further in an $\mathrm{EC} 800^{\mathrm{TM}}$ flow cytometer (SANYO, Osaka, Japan). SYTO BC fluorescence was detected on the FL1 channel (PMT = 5) while PI fluorescence was detected on the FL4 channel (PMT = 3). SYTO BC absorbs at $485-487 \mathrm{~nm}$ and emits at 500-504 nm while PI excitation occurs at $535 \mathrm{~nm}$ and emission at $617 \mathrm{~nm}$.

For all detected parameters, amplification was carried out using logarithmic scales. The cellular concentration was determined by acquiring the counts by the equipment. Multi-parametric analyses were performed on the scattering signals (forward scatter, FSC and side scatter, SSC), as well as on the FL1 (green fluorescence) and FL4 (red fluorescence) channels. When appropriate, a slight adjustment of the gate was made to guarantee the inclusion of the total population in the FCM analysis. For all assays, at least two independent experiments were carried out in duplicate. 


\subsection{Influence of Sonication on Biofilm Cell Viability}

The biofilm suspensions obtained were pooled and sonicated for $30 \mathrm{~s}$ at $30 \%$ amplitude in a sonicator. A non-sonicated sample was included as a control. After this, for each sample, the values of biofilm-culturable cells were determined by CFU counting. On these samples, total cell counting was performed in duplicate for both species.

\subsection{Antimicrobial Effect on Mixed-Species Biofilms}

The antimicrobial effects of the antibiotic ciprofloxacin (Sigma-Aldrich) and the naturally occurring terpene alcohol, linalool (Sigma-Aldrich), were evaluated in mixed-species biofilms of P. aeruginosa PAO1 and C. albicans 547096. For this, 24 h-old pre-established mixed biofilms were exposed to defined concentrations of each antimicrobial: 0.3 or $1.2 \% v / v$ for linalool and 0.25 or $8 \mathrm{mg} / \mathrm{L}$ for ciprofloxacin. The rationale behind the use of these concentrations was based on the assumption that the lower concentrations had already been reported as inhibitory for planktonic culture; then, these concentrations were gradually boosted until we found one that had an inhibitory effect on biofilm without causing total cell eradication. Briefly, after biofilm formation, $500 \mu \mathrm{L}$ of cell suspension was replaced by the antimicrobial solutions prepared at 2 times the desired concentration. Plates were then incubated aerobically at $37^{\circ} \mathrm{C}$ for another $24 \mathrm{~h}$. The results were assessed for biofilm cell culturability through CFU enumeration using selective growth media, as previously described, and by FCM. Both 24 and $48 \mathrm{~h}$-old untreated biofilms were used to infer whether the antimicrobial agents demonstrated a bacteriostatic/bactericidal or fungistatic/fungicidal activity. At least two independent experiments were carried out.

\subsection{Statistical Analysis}

Data were analyzed using the Prism software package (GraphPad Software version 6.01). One-way ANOVA tests were performed, and means were compared by applying Tukey's multiple comparison test. The statistical analyses performed were considered significant when $p<0.05$.

\section{Conclusions}

Overall, the obtained data allow us to strengthen the belief that FCM is a versatile and accurate technique to analyze biofilms; however, it is crucial to take into account some technical aspects to avoid erroneous interpretations. FCM analysis is strain dependent and, as the biofilm matrix is variable for each of microorganism, either grown in isolation or in polymicrobial consortia, the method of extraction (regardless of the one chosen for this purpose) must be personalized for each case. The use of FCM to analyze mixed biofilms challenged by the application of an antimicrobial can provide important insights, explaining the alterations in the behavior of the microbial community and suggesting antimicrobial modes of action in biofilm populations. These outcomes strengthen FCM as a promising technique to study heterogeneous biofilms and evaluate the efficacy of therapeutic approaches.

Throughout this work, the pitfalls related to FCM analysis of inter-kingdom polymicrobial biofilms were fully addressed and efforts were made to circumvent them in order to reliably characterize complex biofilm communities, which are still poorly explored using this approach. This work highlights the fact that this technique can be fruitfully used in the understanding of antimicrobial studies as long as specific and tailored optimization is carried out.

Supplementary Materials: The following are available online at http://www.mdpi.com/2079-6382/9/11/741/s1. Figure S1: Representative dot plots obtained for planktonic and biofilm cells of P. aeruginosa, Figure S2: Representative dot plots obtained for planktonic and biofilm cells of C. albicans, Figure S3: Representative dot plots obtained by FCM of planktonic cells of C. albicans SC5314 (A) and hyphal growth induction (B), Figure S4: Effect of sonication process on biofilm cell viability. CFU enumeration of $C$. albicans (A) and P. aeruginosa (B) biofilms before and after 30 s of sonication at 30\% amplitude, Figure S5: Representative dot plots obtained for P. aeruginosa and C. albicans biofilms (A) and biofilm cells after matrix extraction (B) by FCM. 
Author Contributions: Conceptualization, T.G., A.P.M., L.D.R.M. and M.O.P.; methodology, T.G., A.P.M. and L.D.R.M.; validation, T.G., M.O.P. and L.D.R.M.; formal analysis, T.G., A.P.M. and L.D.R.M.; investigation, T.G., A.P.M. and L.D.R.M.; data curation, T.G.; writing—original draft preparation, T.G.; writing-review and editing, M.O.P., L.D.R.M.; supervision, M.O.P. All authors have read and agreed to the published version of the manuscript.

Funding: This work was supported by the Portuguese Foundation for Science and Technology (FCT) under the scope of the strategic funding of the UID/BIO/04469/2020 unit and BioTecNorte operation (NORTE-01-0145-FEDER-000004), which was funded by the European Regional Development Fund under the scope of Norte2020-Programa Operacional Regional do Norte. The authors also acknowledge COMPETE2020 and FCT under the project POCI-01-0145-FEDER-029841 and FCT for the PhD grant to Tânia Grainha (grant number SFRH/BD/136544/2018).

Conflicts of Interest: The authors declare no conflict of interest.

\section{References}

1. Nickzad, A.; Déziel, E. The involvement of rhamnolipids in microbial cell adhesion and biofilm development-An approach for control? Lett. Appl. Microbiol. 2014, 58, 447-453. [CrossRef] [PubMed]

2. Branda, S.S.; Vik, Å.; Friedman, L.; Kolter, R. Biofilms: The matrix revisited. Trends Microbiol. 2005, 13, $20-26$. [CrossRef] [PubMed]

3. Wingender, J.; Neu, T.R.; Flemming, H.-C. What are Bacterial Extracellular Polymeric Substances? Microb. Extracell. Polym. Subst. 1999, 1-19. [CrossRef]

4. Decho, A.W.; Visscher, P.T.; Reid, R.P. Production and cycling of natural microbial exopolymers (EPS) within a marine stromatolite. Palaeogeogr. Palaeoclim. Palaeoecol. 2005, 219, 71-86. [CrossRef]

5. Peters, B.M.; Jabra-Rizk, M.A.; O’May, G.A.; Costerton, J.W.; Shirtliff, M.E. Polymicrobial interactions: Impact on pathogenesis and human disease. Clin. Microbiol. Rev. 2012, 25, 193-213. [CrossRef] [PubMed]

6. Fourie, R.; Ells, R.; Swart, C.W.; Sebolai, O.M.; Albertyn, J.; Pohl, C.H. Candida albicans and Pseudomonas aeruginosa Interaction, with Focus on the Role of Eicosanoids. Front. Physiol. 2016, 7, 64. [CrossRef]

7. Peleg, A.Y.; Hogan, D.A.; Mylonakis, E. Medically important bacterial-fungal interactions. Nat. Rev. Microbiol. 2010, 8, 340-349. [CrossRef]

8. Mallick, E.M.; Bennett, R.J. Sensing of the microbial neighborhood by Candida albicans. PLoS Pathog. 2013, 9, e1003661. [CrossRef]

9. Hirota, K.; Yumoto, H.; Sapaar, B.; Matsuo, T.; Ichikawa, T.; Miyake, Y. Pathogenic factors in Candida biofilm-related infectious diseases. J. Appl. Microbiol. 2017, 122, 321-330. [CrossRef]

10. Nobile, C.J.; Johnson, A.D. Candida albicans Biofilms and Human Disease. Annu. Rev. Microbiol. 2015, 69, 71-92. [CrossRef]

11. Bianchi, S.M.; Prince, L.R.; McPhillips, K.; Allen, L.; Marriott, H.M.; Taylor, G.W.; Hellewell, P.G.; Sabroe, I.; Dockrell, D.H.; Henson, P.W.; et al. Impairment of apoptotic cell engulfment by pyocyanin, a toxic metabolite of Pseudomonas aeruginosa. Am. J. Respir. Crit. Care Med. 2008, 177, 35-43. [CrossRef] [PubMed]

12. McAlester, G.; O'Gara, F.; Morrissey, J.P. Signal-mediated interactions between Pseudomonas aeruginosa and Candida albicans. J. Med. Microbiol. 2008, 57, 563-569. [CrossRef]

13. Percival, S.L.; Suleman, L.; Vuotto, C.; Donelli, G. Healthcare-Associated infections, medical devices and biofilms: Risk, tolerance and control. J. Med. Microbiol. 2015, 64, 323-334. [CrossRef]

14. Fux, C.A.; Costerton, J.W.; Stewart, P.S.; Stoodley, P. Survival strategies of infectious biofilms. Trends Microbiol. 2005, 13, 34-40. [CrossRef] [PubMed]

15. Carvalhais, V.; Pérez-Cabezas, B.; Oliveira, C.; Vitorino, R.; Vilanova, M.; Cerca, N. Tetracycline and rifampicin induced a viable but nonculturable state in Staphylococcus epidermidis biofilms. Future Microbiol. 2018, 13, 27-36. [CrossRef] [PubMed]

16. Vuong, J.; Collard, J.-M.; Whaley, M.J.; Bassira, I.; Seidou, I.; Diarra, S.; Ouédraogo, R.T.; Kambiré, D.; Taylor, T.H.; Sacchi, C.; et al. Development of Real-Time PCR Methods for the Detection of Bacterial Meningitis Pathogens without DNA Extraction. PLoS ONE 2016, 11, e0147765. [CrossRef]

17. Zemanick, E.T.; Wagner, B.D.; Sagel, S.D.; Stevens, M.J.; Accurso, F.J.; Harris, J.K. Reliability of quantitative real-time PCR for bacterial detection in cystic fibrosis airway specimens. PLoS ONE 2010, 5, e15101. [CrossRef] 
18. Rodrigues, M.E.; Lopes, S.P.; Pereira, C.R.; Azevedo, N.F.; Lourenço, A.; Henriques, M.; Pereira, M.O. Polymicrobial Ventilator-Associated Pneumonia: Fighting In Vitro Candida albicans-Pseudomonas aeruginosa Biofilms with Antifungal-Antibacterial Combination Therapy. PLoS ONE 2017, 12, e0170433. [CrossRef]

19. Machado, A.; Almeida, C.; Salgueiro, D.; Henriques, A.; Vaneechoutte, M.; Haesebrouck, F.; Vieira, M.J.; Rodrigues, L.; Azevedo, N.F.; Cerca, N. Fluorescence in situ Hybridization method using Peptide Nucleic Acid probes for rapid detection of Lactobacillus and Gardnerella spp. BMC Microbiol. 2013, 13, 82. [CrossRef]

20. Almeida, C.; Azevedo, N.F.; Bento, J.C.; Cerca, N.; Ramos, H.; Vieira, M.J.; Keevil, C.W. Rapid detection of urinary tract infections caused by Proteus spp. using PNA-FISH. Eur. J. Clin. Microbiol. Infect. Dis. 2013, 32, 781-786. [CrossRef]

21. Müller, S.; Nebe-von-Caron, G. Functional single-cell analyses: Flow cytometry and cell sorting of microbial populations and communities. FEMS Microbiol. Rev. 2010, 34, 554-587. [CrossRef]

22. Davey, H.M.; Kell, D.B. Flow cytometry and cell sorting of heterogeneous microbial populations: The importance of single-cell analyses. Microbiol. Rev. 1996, 60, 641-696. [CrossRef] [PubMed]

23. Kucharíková, S.; lè ne Tournu, H.; Lagrou, K.; Van Dijck, P.; Bujdá ková, H. Detailed comparison of Candida albicans and Candida glabrata biofilms under different conditions and their susceptibility to caspofungin and anidulafungin. J. Med. Microbiol. 2011, 60, 1261-1269. [CrossRef] [PubMed]

24. Cheng, M.; Cook, A.E.; Fukushima, T.; Bond, P.L. Evidence of compositional differences between the extracellular and intracellular DNA of a granular sludge biofilm. Lett. Appl. Microbiol. 2011, 53, 1-7. [CrossRef]

25. Martins, N.; Costa-Oliveira, S.; Melo, L.D.R.; Ferreira, I.C.F.R.; Azeredo, J.; Henriques, M.; Silva, S. Susceptibility testing of Candida albicans and Candida glabrata to Glycyrrhiza glabra L. Ind. Crops Prod. 2017, 108, 480-484. [CrossRef]

26. Cerca, F.; Trigo, G.; Correia, A.; Cerca, N.; Azeredo, J.; Vilanova, M. SYBR green as a fluorescent probe to evaluate the biofilm physiological state of Staphylococcus epidermidis, using flow cytometry. Can. J. Microbiol. 2011, 57, 850-856. [CrossRef] [PubMed]

27. Kerstens, M.; Boulet, G.; Van Kerckhoven, M.; Clais, S.; Lanckacker, E.; Delputte, P.; Maes, L.; Cos, P. A flow cytometric approach to quantify biofilms. Folia Microbiol. 2015, 60, 335-342. [CrossRef]

28. Oliveira, F.; Lima, C.A.; Brás, S.; França, Â.; Cerca, N. Evidence for inter- and intraspecies biofilm formation variability among a small group of coagulase-negative staphylococci. FEMS Microbiol. Lett. 2015, 362, fnv175. [CrossRef]

29. Pan, H.; Zhang, Y.; He, G.-X.; Katagori, N.; Chen, H. A comparison of conventional methods for the quantification of bacterial cells after exposure to metal oxide nanoparticles. BMC Microbiol. 2014, 14, 222. [CrossRef]

30. Rüger, M.; Bensch, G.; Tüngler, R.; Reichl, U. A flow cytometric method for viability assessment of Staphylococcus aureus and Burkholderia cepacia in mixed culture. Cytom. Part A 2012, 81A, 1055-1066. [CrossRef] [PubMed]

31. Cos, P.; Toté, K.; Horemans, T.; Maes, L. Biofilms: An extra hurdle for effective antimicrobial therapy. Curr. Pharm. Des. 2010, 16, 2279-2295. [CrossRef]

32. Ramage, G.; Saville, S.P.; Thomas, D.P.; Lopez-Ribot, J.L. Candida Biofilms: An Update. Eukaryot. Cell 2005, 4, 633-638. [CrossRef] [PubMed]

33. Vilain, S.; Pretorius, J.M.; Theron, J.; Brözel, V.S. DNA as an adhesin: Bacillus cereus requires extracellular DNA to form biofilms. Appl. Environ. Microbiol. 2009, 75, 2861-2868. [CrossRef] [PubMed]

34. Tsuneda, S.; Aikawa, H.; Hayashi, H.; Yuasa, A.; Hirata, A. Extracellular polymeric substances responsible for bacterial adhesion onto solid surface. FEMS Microbiol. Lett. 2003, 223, 287-292. [CrossRef]

35. Hancock, R.E.W. A brief on bacterial biofilms. Nat. Genet. 2001, 29, 360. [CrossRef] [PubMed]

36. Flemming, H.-C.; Wingender, J. The biofilm matrix. Nat. Rev. Microbiol. 2010, 8, 623. [CrossRef] [PubMed]

37. Nielsen, P.H.; Jahn, A. Extraction of EPS. In Microbial Extracellular Polymeric Substances; Springer: Berlin/Heidelberg, Germany, 1999; pp. 49-72.

38. Dosler, S.; Karaaslan, E. Inhibition and destruction of Pseudomonas aeruginosa biofilms by antibiotics and antimicrobial peptides. Peptides 2014, 62, 32-37. [CrossRef]

39. Serra, E.; Hidalgo-Bastida, L.A.; Verran, J.; Williams, D.; Malic, S. Antifungal activity of commercial essential oils and biocides against Candida albicans. Pathogens 2018, 7, 15. [CrossRef] 
40. Martínez, J.L. Effect of antibiotics on bacterial populations: A multi-hierachical selection process. F1000Research 2017, 6, 51. [CrossRef]

41. Van Bambeke, F.; Michot, J.-M.; Van Eldere, J.; Tulkens, P.M. Quinolones in 2005: An update. Clin. Microbiol. Infect. 2005, 11, 256-280. [CrossRef]

42. Silva, F.; Lourenço, O.; Queiroz, J.A.; Domingues, F.C. Bacteriostatic versus bactericidal activity of ciprofloxacin in Escherichia coli assessed by flow cytometry using a novel far-red dye. J. Antibiot. 2011, 64, 321-325. [CrossRef] [PubMed]

43. Høiby, N.; Ciofu, O.; Johansen, H.K.; Song, Z.J.; Moser, C.; Jensen, P.Ø.; Molin, S.; Givskov, M.; Tolker-Nielsen, T.; Bjarnsholt, T. The Clinical Impact of Bacterial Biofilms. Int. J. Oral Sci. 2011, 3, 55-65. [CrossRef]

44. Oliveira, A.; Ribeiro, H.G.; Silva, A.C.; Silva, M.D.; Sousa, J.C.; Rodrigues, C.F.; Melo, L.D.R.; Henriques, A.F.; Sillankorva, S. Synergistic antimicrobial interaction between honey and phage against Escherichia coli biofilms. Front. Microbiol. 2017, 8, 2407. [CrossRef]

45. Fostel, J.M.; Montgomery, D.A.; Shen, L.L. Characterization of DNA topoisomerase I from Candida albicans as a target for drug discovery. Antimicrob. Agents Chemother. 1992, 36, 2131-2138. [CrossRef] [PubMed]

46. Shen, L.L.; Baranowski, J.; Fostel, J.; Montgomery, D.A.; Lartey, P.A. DNA topoisomerases from pathogenic fungi: Targets for the discovery of antifungal drugs. Antimicrob. Agents Chemother. 1992, 36, 2778-2784. [CrossRef] [PubMed]

47. Shen, L.L.; Fostel, J.M. DNA Topoisomerase Inhibitors as Antifungal Agents. In Advances in Pharmacology; Academic Press: New York, NY, USA, 1994; Volume 29, pp. 227-244.

48. Stergiopoulou, T.; Meletiadis, J.; Sein, T.; Papaioannidou, P.; Tsiouris, I.; Roilides, E.; Walsh, T.J. Isobolographic analysis of pharmacodynamic interactions between antifungal agents and ciprofloxacin against Candida albicans and Aspergillus fumigatus. Antimicrob. Agents Chemother. 2008, 52, 2196-2204. [CrossRef]

49. Brilhante, R.S.N.; Caetano, E.P.; Sidrim, J.J.C.; Cordeiro, R.A.; Camargo, Z.P.; Fechine, M.A.B.; Lima, R.A.C.; Castelo Branco, D.S.C.M.; Marques, F.J.F.; Mesquita, J.R.L.; et al. Ciprofloxacin shows synergism with classical antifungals against Histoplasma capsulatum var. capsulatum and Coccidioides posadasii. Mycoses 2013, 56, 397-401. [CrossRef]

50. Stergiopoulou, T.; Meletiadis, J.; Sein, T.; Papaioannidou, P.; Tsiouris, I.; Roilides, E.; Walsh, T.J. Comparative pharmacodynamic interaction analysis between ciprofloxacin, moxifloxacin and levofloxacin and antifungal agents against Candida albicans and Aspergillus fumigatus. J. Antimicrob. Chemother. 2009, 63, 343-348. [CrossRef]

51. Zore, G.B.; Thakre, A.D.; Jadhav, S.; Karuppayil, S.M. Terpenoids inhibit Candida albicans growth by affecting membrane integrity and arrest of cell cycle. Phytomedicine 2011, 18, 1181-1190. [CrossRef]

52. Alviano, W.S.; Mendonca-Filho, R.R.; Alviano, D.S.; Bizzo, H.R.; Souto-Padron, T.; Rodrigues, M.L.; Bolognese, A.M.; Alviano, C.S.; Souza, M.M.G.; Mendonça-Filho, R.R.; et al. Antimicrobial activity of Croton cajucara Benth linalool-rich essential oil on artificial biofilms and planktonic microorganisms. Oral Microbiol. Immunol. 2005, 20, 101-105. [CrossRef]

53. Hsu, C.-C.; Lai, W.-L.; Chuang, K.-C.; Lee, M.-H.; Tsai, Y.-C. The inhibitory activity of linalool against the filamentous growth and biofilm formation in Candida albicans. Med. Mycol. 2013, 51, 473-482. [CrossRef]

54. Léonard, L.; Chibane, L.B.; Bouhedda, B.O.; Degraeve, P.; Oulahal, N. Recent advances on multi-parameter flow cytometry to characterize antimicrobial treatments. Front. Microbiol. 2016, 7, 1225. [CrossRef] [PubMed]

55. Pasquaroli, S.; Zandri, G.; Vignaroli, C.; Vuotto, C.; Donelli, G.; Biavasco, F. Antibiotic pressure can induce the viable but non-culturable state in Staphylococcus aureus growing in biofilms. J. Antimicrob. Chemother. 2013, 68, 1812-1817. [CrossRef]

56. Li, L.; Mendis, N.; Trigui, H.; Oliver, J.D.; Faucher, S.P. The importance of the viable but non-culturable state in human bacterial pathogens. Front. Microbiol. 2014, 5, 258. [CrossRef] [PubMed]

57. Khan, A.; Ahmad, A.; Akhtar, F.; Yousuf, S.; Xess, I.; Khan, L.A.; Manzoor, N. Ocimum sanctum essential oil and its active principles exert their antifungal activity by disrupting ergosterol biosynthesis and membrane integrity. Res. Microbiol. 2010, 161, 816-823. [CrossRef] [PubMed]

58. Soković, M.; Glamočlija, J.; Marin, P.D.; Brkić, D.; Griensven, L.J.L.D. van Antibacterial Effects of the Essential Oils of Commonly Consumed Medicinal Herbs Using an In Vitro Model. Molecules 2010, 15, 7532-7546. [CrossRef] [PubMed] 
59. Costa, S.P.; Dias, N.M.; Melo, L.D.R.; Azeredo, J.; Santos, S.B.; Carvalho, C.M. A novel flow cytometry assay based on bacteriophage-derived proteins for Staphylococcus detection in blood. Sci. Rep. 2020, 10, 1-13. [CrossRef]

60. Stepanović, S.; Vuković, D.; Dakić, I.; Savić, B.; Švabić-Vlahović, M. A modified microtiter-plate test for quantification of staphylococcal biofilm formation. J. Microbiol. Methods 2000, 40, 175-179. [CrossRef]

61. Silva, S.; Henriques, M.; Martins, A.; Oliveira, R.; Williams, D.; Azeredo, J. Biofilms of non-Candida albicans Candida species: Quantification, structure and matrix composition. Med. Mycol. 2009, 47, 681-689. [CrossRef]

Publisher's Note: MDPI stays neutral with regard to jurisdictional claims in published maps and institutional affiliations.

(C) 2020 by the authors. Licensee MDPI, Basel, Switzerland. This article is an open access article distributed under the terms and conditions of the Creative Commons Attribution (CC BY) license (http://creativecommons.org/licenses/by/4.0/). 